\title{
Regeneration of Activated Carbon Sutured Hexavalent Chrome
}

\author{
K. Elmerzouki ${ }^{1, *}$, I. Bimaghra ${ }^{1}$ and A. Khalidi ${ }^{2}$ \\ ${ }^{1}$ UH2C, Ecole Normale Supérieur, Laboratoire Ingénierie des Matériaux et Biosciences, Casablanca Morocco \\ ${ }^{2}$ UH2C, FST, Mohammedia, Morocco
}

\begin{abstract}
In order to prevent a simple pollution transfer and for the purpose of valorization of the process of activated carbon treatment, this one, saturated with pollutants should not increase the pollution mass of household waste. Indeed, an adsorbent offers a real interest only if it can be easily regenerated. This work addresses to the becoming the activated carbon after being saturation with hexavalent chromium. The activated carbon should not be stored directly, since the acid rain waters might leach some heavy metals. This would contaminate the soil and water resources. For this, it should be treated after use and returned to its original structure and chemical composition for an eventual future use with a good yield of re-adsorption. Within this work, the use of a base $(\mathrm{KOH})$ has recovered an amount of hexavalent chromium retained by the activated carbon $\mathrm{CAB}$. This one, regenerated was again used to secure the hexavalent chromium ions during several cycles. Regeneration test results have shown that the efficacy of $C A B$ remains almost constant during the first four cycles of reuse and then decreases during the fifth cycle.
\end{abstract}

Keywords: Activated carbon, chromium VI, regeneration, recycling.

\section{INTRODUCTION}

In order to prevent a simple pollution transfer and for the purpose of valorization of the process of activated carbon treatment, this one, saturated with pollutants should not increase the pollution mass of household waste.

Most prior work relating to the regeneration study on organic materials, the essential element used as regenerating is $\mathrm{H}_{3} \mathrm{O}^{+}$ion. Thus, Garg [1] studied the removal of chromium $(\mathrm{VI})$ by Indian red wood sawyers treated with sulfuric acid. The recovery of chromium $(\mathrm{VI})$ is done by simply washing with the mixture $(\mathrm{NaOH}$, $\mathrm{HCl}$ ). Muzzarelli [2] exploited the chitin to recover heavy metals from seawater. These metals are then recovered by an appropriate washing with acid. Haung [3] studied the regeneration of fungi biomass charged by $\mathrm{Cd}^{2+}$. It was found that these materials can be regenerated by strong acids. Hoshi [4] exploited the chitin in the determination of copper adsorption-elution on column. $\mathrm{Cu}^{2+}$ retained was eluted by a mixture of acetic acid and acetone. Roy [8] showed that most of the heavy metals can be recovered by decreasing the $\mathrm{pH}$ of the medium, using an acid wash.

This work is devoted to the future of activated carbon after its saturation with hexavalent chromium. Indeed, the activated carbon can't be stored directly, since the acid water rains might leach some of the heavy metals attached, that would contaminate the soil and water resources. In order to avoid the

*Correspondence Address to this author at the UH2C, Ecole Normale Supérieur, Laboratoire Ingénierie des Matériaux et Biosciences, Casablanca Morocco; Tel: 0662267222; E-mail: elmer_khad@yahoo.fr displacement of pollution, the activated carbon used for decontamination of industrial effluents should be treated after use. Some methods are feasible:

- The elution: it provides a concentrated solution of low volume, suitable for precipitation processes for the possible recycling of heavy metal compounds and substrate reuse.

- The incineration: it generates ashes enriched on metal oxides. These ashes can be recycled if heavy metal content is appropriate to specifications of metallurgy units, or disposed in landfill site after treatment. Given its low volume, the cost of storage is reduced.

- $\quad$ The pyrolysis: it produces residues that contain heavy metals and carbon materials. These residues are also recyclable in secondary metal production, or disposed in landfill site after treatment.

One of these methods may be selected as an appropriate treatment of waste saturated with heavy metals, according to various criteria: the physical and chemical characteristics of the elements or their compounds, their economic value, etc. The biodegradation of these waste substrates is an alternative treatment at the end of life cycle.

Indeed, an adsorbent offers a real interest only if it can be easily regenerated. The activated carbon used in the retention of pollutants must regain its original structure and chemical composition of departure for future use with appreciable yield of re-adsorption. 
Considering all the work related to this issue, we opted for the following of this work to the valorization of activated carbon by the study of its regeneration by elution with a basic solution $\mathrm{NaOH}$ or $\mathrm{KOH}$.

\section{MATERIALS AND METHODS}

\subsection{Products Used}

Potassium dichromate $\mathrm{K}_{2} \mathrm{Cr}_{2} \mathrm{O}_{7}$, sodium hydroxide $(\mathrm{NaOH})$, the diphenylcarbazide acid is prepared from the acid 1,5-diphenylcarbazide 97\%, ethanol 95\%, potassium hydroxide $(\mathrm{KOH})$ and the sulfuric acid $95 \%$ of analytical grade are used in this study.

\subsection{Experimental Protocol}

The study of regeneration of hexavalent chromium fixed to $C A B$ was performed using the device in agitated bath according to the following experimental protocol:

$0.3 \mathrm{~g}$ of $\mathrm{CAB}$ saturated with $\mathrm{Cr}(\mathrm{VI})+50 \mathrm{~mL} \mathrm{KOH}$ or $\mathrm{NaOH}(0.5 \mathrm{M})$.

Agitation 3 hours at $\mathrm{T}=20 \pm 2{ }^{\circ} \mathrm{C}$.

Filtering the mixture.

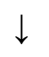

Analysis of the concentration of $\mathrm{Cr}(\mathrm{VI})$ in the filtrate.

Schematic of the experimental protocol for regeneration of activated carbon.

\section{RESULTS AND DISCUSSION}

\subsection{Regeneration of Active Carbon}

\subsubsection{Study of the Release of $\mathrm{Cr}(\mathrm{VI})$ lons}

After the regeneration test, we measured the concentration of the hexavalent chromium ion released

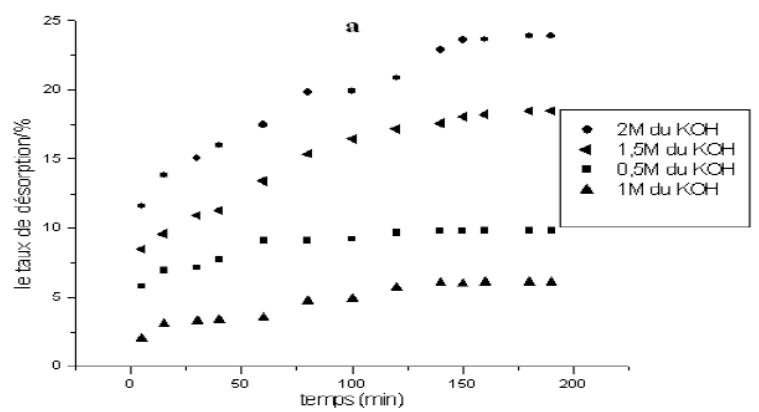

for each of the bases $\mathrm{NaOH}$ and $\mathrm{KOH}$ used [6]. The results are summarized in Figure 1.

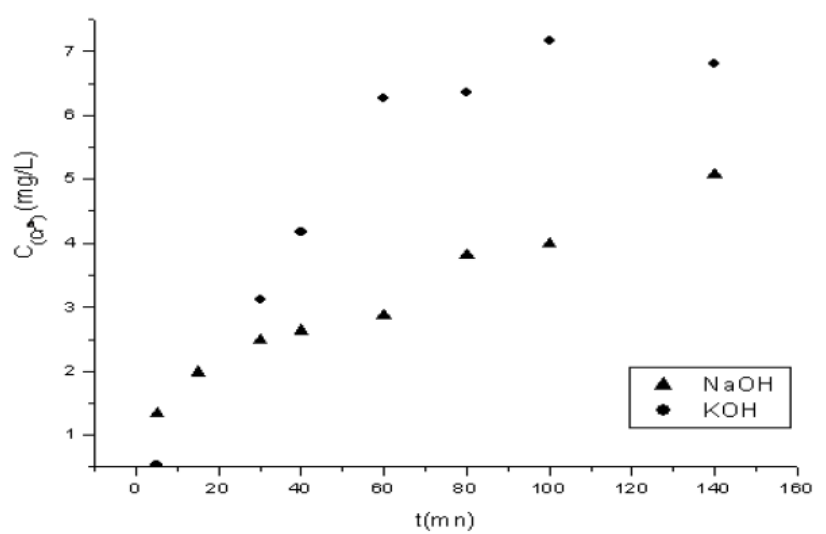

Figure 1: Variation of the concentration of released $\mathrm{Cr}(\mathrm{VI})$ ions as function of time. $m_{a d s}=0.3 \mathrm{~g}, C_{0}=0 \mathrm{mg} / \mathrm{L} \mathrm{V}=50 \mathrm{~mL}$ et $v_{\text {agitation }}=150 \mathrm{Tr} / \mathrm{min}$.

The two curves show that the concentration of chromium $\mathrm{Cr}(\mathrm{VI})$ ions released increases with time [6]. This concentration reaches a maximum of $7.17 \mathrm{mg} / \mathrm{L}$ after $100 \mathrm{~min}$ of stirring in a solution of $\mathrm{KOH}$ base. However, it reached a value of $4.00 \mathrm{mg} / \mathrm{L}$ after $100 \mathrm{~min}$ of stirring in a solution of $\mathrm{NaOH}$ base.

According to these results, it is found that there is a releasing of ion $\mathrm{Cr}(\mathrm{VI})$ by the addition of $\mathrm{Na}^{+}$or $\mathrm{K}^{+}$. The release increases with time to reach $5.07 \mathrm{mg} / \mathrm{L}$ in the case of $11.5 \mathrm{~g} / \mathrm{L}$ of $\mathrm{Na}^{+}$and $6.80 \mathrm{mg} / \mathrm{L}$ in the case of $19.5 \mathrm{~g} / \mathrm{L}$ of $\mathrm{K}^{+}$. During the regeneration, the amount of $\mathrm{K}^{+}$set by the loaded activated carbon by $\mathrm{Cr}(\mathrm{VI})$ is greater than the amount of $\mathrm{Na}^{+}$set by this latter. As follows, we will use the base $\mathrm{KOH}$ for regeneration.

\subsubsection{Displacement of lons $\mathrm{Cr}(\mathrm{VI})$ by $\mathrm{K}^{+}$Cations}

Desorption can regenerate chromium adsorbed onto activated carbon. It takes place in a basic solution of $\mathrm{KOH}$ with different concentrations $0.5,1,1.5$ and 2 $M$. The results given in Figure 2a shows that the released amount of $\mathrm{Cr}(\mathrm{VI})$ increases with time for each

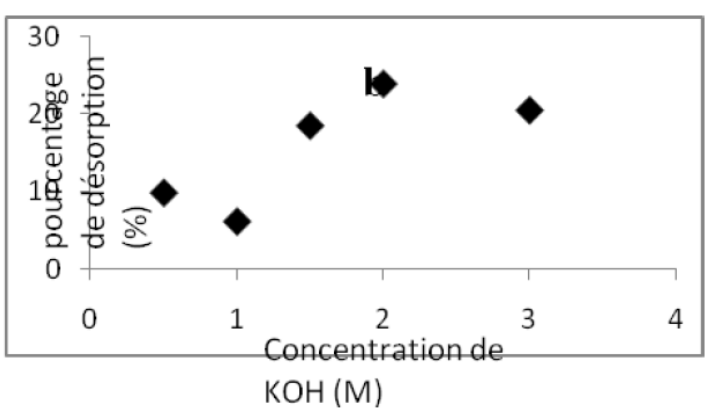

Figure 2: Study of the desorption of $\mathrm{Cr}(\mathrm{VI})$ as a function of a: the desorption rate as a function of the $\mathrm{K}+\mathrm{concentration}$ and agitation time; $\mathrm{b}$ : desorption rate as a function of the $\mathrm{K}+$ concentration. mads $=0.9 \mathrm{~g}, \mathrm{~h} \mathrm{t}=3, \mathrm{~V}=150 \mathrm{~mL}$ and $\mathrm{v}=150 \mathrm{r} / \mathrm{min}$. 
$\mathrm{KOH}$ concentration used and reach a maximum value of $9.83 \%, 6.11 \%, 18.54 \%$ and $23.9 \%$ for the concentrations of $\mathrm{K}^{+} 0.5,1,1.5$ and $2 \mathrm{M}$ successively, and then it is stabilized at these values.

The released amount of $\mathrm{Cr}(\mathrm{VI})$ adsorbed on $\mathrm{CAB}$ increases as the $\mathrm{K}^{+}$concentration increases [7]. The maximum amount released is recorded (Figure $\mathbf{2 b}$ ) for a concentration of $\mathrm{K}^{+} 2 \mathrm{M}$, in which the percentage of releasing is the highest $24 \%$, this value is reached after $2 \mathrm{~h} 30 \mathrm{~min}$ of stirring.

For the rest of this work and in the same experimental conditions, we will set the $\mathrm{K}^{+}$ concentration used to $2 \mathrm{M}$.

\subsection{Recycling of Activated Carbon Loaded with $\mathrm{Cr}(\mathrm{VI})$}

\subsubsection{Successive Adsorption-Regeneration Cycles with Drying}

The results of the releasing tests reported above have shown that it is possible to recover metals fixed on the activated carbon. It is therefore interesting to examine possible reuse of the latter and to study the variation of the retention capacity during several successive cycles.

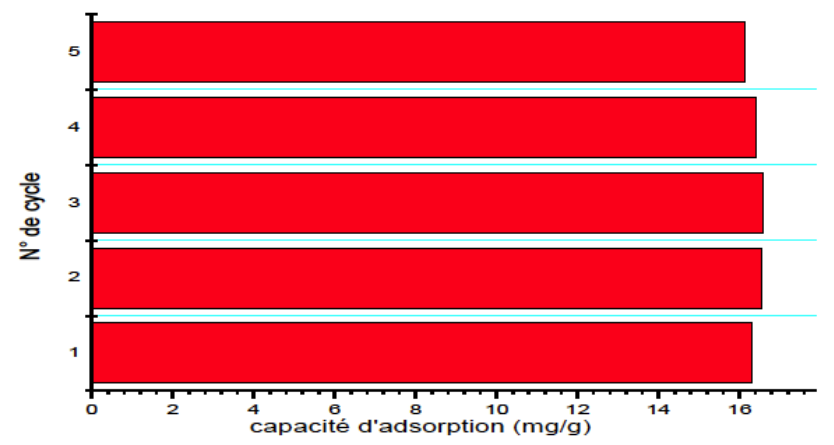

Figure 3: Evolution of the retention capacity of $\mathrm{Cr}(\mathrm{VI})$ by activated carbon as a function of number of reuse cycles $m_{\text {ads }}$ $=0.3 \mathrm{~g}, \mathrm{t}=2 \mathrm{~h}, \mathrm{~V}=50 \mathrm{~mL},\left[\mathrm{~K}^{+}\right]=2 \mathrm{M}$ and $\mathrm{v}=150 \mathrm{Tr} / \mathrm{min}$.

Figure 3 shows the evolution of the retention capacity of $\mathrm{Cr}(\mathrm{VI})$ by activated carbon CABRS, regenerated with drying during recycling, depending on number of reuse cycles. We find that the retention capacity increases slightly after the first cycle and decreases after the third cycle. It passes from 16.6 $\mathrm{mg} / \mathrm{L}$ of $\mathrm{Cr}(\mathrm{VI})$ in the fourth cycle to $16.1 \mathrm{mg} / \mathrm{g}$ of $\mathrm{Cr}(\mathrm{VI})$ in the fifth cycle. This represents a loss of about $2.89 \%$ of the effectiveness of activated carbon between the third and the fifth cycle. Similar results were found by Shubo Deng who studied the retention of $\mathrm{Cr}(\mathrm{VI})$ by amino polyacrylonitrile fibers [7]. This may be attributed to the leaching of a portion of organic matter and microorganism by the base used in the regeneration. This can cause a decrease in the number of ion binding sites of heavy metals and therefore their retention capacity.

\subsubsection{Successive Adsorption Cycles without Regeneration and with Drying during Each Cycle}

Figure 4 shows the evolution of the retention capacity of $\mathrm{Cr}(\mathrm{VI})$ adsorbed to the activated carbon CABNRS (unregenerate with drying after each adsorption cycle).

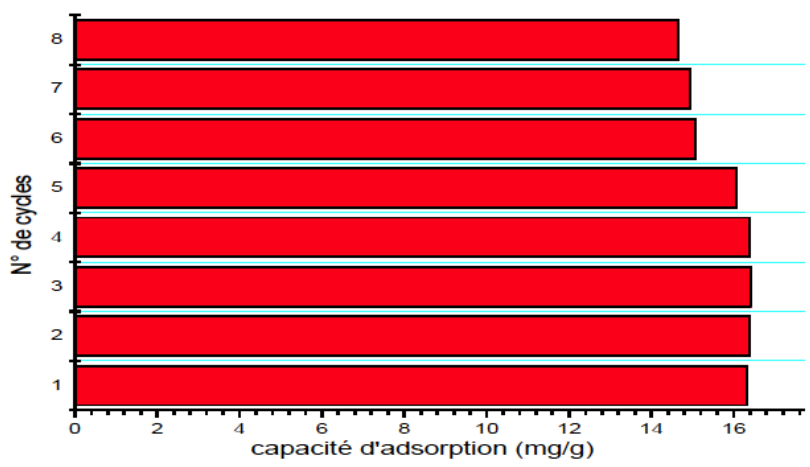

Figure 4: Evolution of the retention capacity of $\mathrm{Cr}(\mathrm{VI})$ by activated carbon as a function of number of reuse cycles mads $=0.3 \mathrm{~g}, \mathrm{t}=2 \mathrm{~h}, \mathrm{~V}=50 \mathrm{~mL},\left[\mathrm{~K}^{+}\right]=2 \mathrm{M}$ and $\mathrm{v}=150 \mathrm{Tr} / \mathrm{min}$.

The application of this method requires no energy. So, ecologically, it's the most suitable for recycling activated carbon.

\subsubsection{Successive Desorption Cycles}

The experimental results related to the evolution of the capacity of the release of $\mathrm{Cr}(\mathrm{VI})$ ions by activated carbon depending on the number of cycles (Figure 5) show a clear decrease of the release capacity which could reach near zero values if we went beyond 6 th cycle.

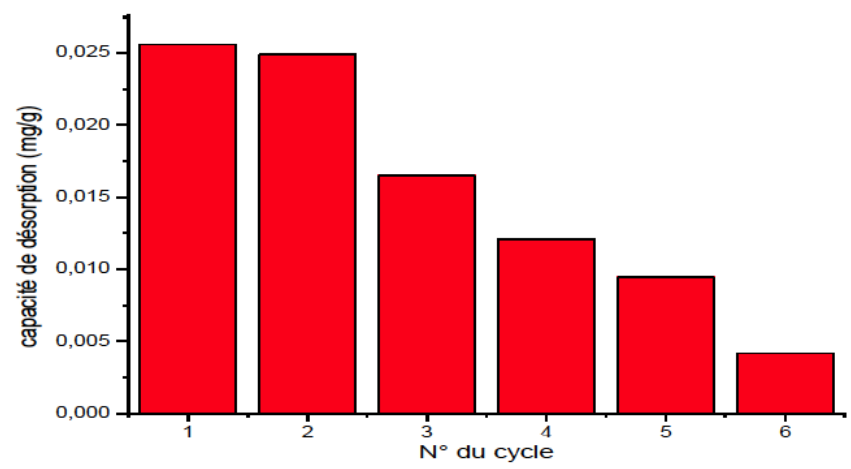

Figure 5: Evolution of the release capacity of $\mathrm{Cr}(\mathrm{VI})$ by the activated carbon as a function of number of wash cycles $m_{\text {ads }}$ $=0.3 \mathrm{~g}, \mathrm{t}=2 \mathrm{~h}, \mathrm{~V}=50 \mathrm{~mL},\left[\mathrm{~K}^{+}\right]=2 \mathrm{M}$ and $\mathrm{v}=150 \mathrm{Tr} / \mathrm{min}$. 


\subsection{Comparison of Results}

Comparing the above results, we can observe that the adsorption capacity of $\mathrm{Cr}(\mathrm{VI})$ on activated carbon is nearly constant at $16.4 \mathrm{mg} / \mathrm{g}$ for CABNR, $16.6 \mathrm{mg} / \mathrm{g}$ for CABNRS and $16.5 \mathrm{mg} / \mathrm{g}$ for CABRS) in the first five cycles.

From ecological point of view, recycling of activated carbon CABNRS, unregenerate and drying is the most effective. In order not to cause another pollution problem, it will be treated with more chromium hexavalent desorption cycles before storage. However, the regeneration of activated carbon is a hindered process that requires the addition of reagents (base or acid) [6]. In addition, regeneration changes the structure of materials. But despite this, it remains the best solution in the case of mineral effluents heavily loaded with heavy metals and the composition is simple.

\section{CONCLUSION}

This study evaluates qualitatively and quantitatively activated carbon. Treatment of activated carbon saturated with hexavalent chromium helps the mitigation of adverse effects of this material to the environment and the reuse of it as adsorbent, besides its possible recycling of metal compounds. The three recycling methods used in this work are: successive adsorption-desorption cycles, successive adsorption cycles with drying of the activated carbon and successive adsorption cycles without drying of the activated carbon.

The use of a base $(\mathrm{KOH})$ has recovered an amount of hexavalent chromium retained by the activated carbon $C A B$. This $C A B$ regenerated was again used to set the hexavalent chromium ions during several cycles. Regeneration test results showed that the effectiveness of the $C A B$ remains almost constant during the first four cycles and then decreases from the fifth cycle.

On the other hand, it appears that the effectiveness of the activated carbon does not change during their reuse for the removal of metal ions in solution. Activated carbon may eventually replace ion exchange resins in the processing units of industrial effluents containing heavy metals.

\section{REFERENCES}

[1] Garg VK, Gupta R, Kumar R, Gupta RK. Adsorption of chromium from aqueous solution on treated sawdust. Bioressources Technologique 2003; 92: 79-84. http://dx.doi.org/10.1016/j.biortech.2003.07.004

[2] Muzzarelli RAA. Chitin and chitosane as chromatographic supports and adsorbents for collection of metal ions from organic and aqueous solutions and sea water. Official Gazette of the United States Pattem Office 1972; 894(3): 1093.

[3] Haung P, Morehart AL, Westman DC. Removal of toxic heavy metals from contaminated ground water by a fungal adsorption process. Water Science and Technology 1989; 20(11/12): 369-376.

http://dx.doi.org/10.2116/analsci.5.471

[4] Hoshi S, Tanaka $Y$, Inoue S, Matsubara M. Spectrophotometric determination of trace coper after adsorption and elution of neocuproine complexe on chitin. Analytical Sciences 1989.

[5] Kupryianchyk D, Rakowska MI, Grotenhuis JTC, Koelmans AA. In situ sorption of hydrophobic organic compounds to sediment amended with activated carbon. Environmental Pollution 2012; 161: 23-29. http://dx.doi.org/10.1016/j.envpol.2011.09.043

[6] Takahashi N, Ushiki I, Hamabe Y, Ota M, Sato Y, Inomata H. Measurement and prediction of desorption behavior of five volatile organic compounds (acetone, $\mathrm{n}$-hexane, methanol, toluene, and n-decane) from activated carbon for supercritical carbon dioxide regeneration. The Journal of Supercritical Fluids Volume 2015; 107: 226-233. http://dx.doi.org/10.1016/j.supflu.2015.09.014

[7] Abioye AM, Ani FN. Recent development in the production of activated carbon electrodes from agricultural waste biomass for supercapacitors: A review. Renewable and Sustainable Energy Reviews 2015; 52: 1282-1293. http://dx.doi.org/10.1016/j.rser.2015.07.129

[8] Roy D. Nouveau procédé de dépollution des effluents industriels contenant des métaux lourds. Thèse, 139 pages, INPL, Vandoeouvre, France 1993. 